\title{
MARCEL MAUSS: DA DÁDIVA À QUESTÃo DA RECIPROCIDADE*
}

\section{Eric Sabourin}

\section{Introdução}

Depois dos inúmeros e qualificados escritos e comentários produzidos a propósito do Ensaio sobre a dádiva, e da produção cada vez mais importante das ciências sociais brasileiras sobre $\mathrm{O}$ tema,${ }^{1}$ o que agregar sem ser repetitivo ou pretensioso? Neste texto abordarei apenas a questão da relação entre as noções de dádiva, troca ${ }^{2}$ e reciprocidade $^{3}$ no Ensaio de Marcel Mauss, apoiando-me em algumas publicações recentes e sem pretender ser exaustivo. Desenvolverei uma reflexão em torno de um duplo paradoxo do Ensaio sobre a dádi-

* Uma versão preliminar desse texto foi apresentada na Sessão Especial "Marcel Mauss e as Ciências Sociais" do XXX Encontro Anual da Anpocs, Caxambu - MG.

Artigo recebido em janeiro/2007

Aprovado em dezembro/2007 va (que passou a fazer parte do livro Sociologia e antropologia, 1950).

De um lado, Mauss evidencia que a dádiva é o oposto da troca mercantil e, paradoxalmente, procura nela a origem da troca (ou do intercâmbio). De outro lado, mostra a essência da reciprocidade com o caráter universal da tríplice obrigação de "dar, receber e retribuir", mas não chega a teorizar sobre tal reciprocidade ${ }^{4}$, trabalho que deixou para seus seguidores, em particular Lévi-Strauss (1967 [1947], 1997 [1950]) e, mais recentemente, Temple e Chabal (1995), Temple (1998, 2003), Godbout (2000, 2007), entre outros.

Mas não há consenso entre os seguidores e estudiosos do Ensaio sobre a dádiva. Sigaud (1999) mostra, assim, uma descontinuidade da herança de Mauss e, sobretudo, as diversas interpretações, às vezes contraditórias, que foram feitas do Ensaio. A autora analisa como Lévi-Strauss (1997 [1950]) utilizou partes do Ensaio... para justificar sua teo- 
ria da troca generalizada e da troca simbólica. Devemos a Temple e Chabal (1995 e 2003) uma explicação renovada das contribuições respectivas de Mauss e de Lévi-Strauss para a teoria da reciprocidade.

Esse duplo paradoxo no Ensaio... leva, portanto, às duas partes da minha reflexão. A primeira trata da dádiva como algo contrário à troca e não como sua origem. A segunda aborda alguns elementos de leitura empírica do princípio de reciprocidade no Ensaio... Proponho um breve esboço de síntese desses ensinamentos e das perspectivas que se abrem na terceira parte deste texto.

\section{A dádiva como contrário da troca}

Para Mauss, as prestações primitivas revestem a forma de dádivas, de presentes, reguladas por três obrigações interligadas: dar, receber, retribuir (Mauss, 2003, pp. 200 e 243). Dar é uma obrigação, sob a pena de provocar uma guerra (Idem, p 201). Cada uma dessas obrigações cria um laço de energia espiritual entre os atores da dádiva. A retribuição da dádiva seria explicada pela existência dessa força, dentro da coisa dada: um vínculo de almas, associado de maneira inalienável ao nome do doador, ou seja, ao seu prestígio. A essa força ou ser espiritual ou à sua expressão simbólica ligada a uma ação ou transação, Mauss dará o nome polinésio de mana.

Em primeiro lugar, Mauss mal resolve qualificar de "troca" as relações que está analisando. De um lado, ele encontra nas sociedades indígenas formas de troca que não correspondem "a nossa", no sistema ocidental.

Descreveremos os fenômenos de troca e de contrato nessas sociedades que são, não privadas de mercados econômicos como se afirmou - pois o mercado é um fenômeno humano que, a nosso ver, não é alheio a nenhuma sociedade conhecida -, mas cujo regime de troca é diferente do nosso (Idem, p.188).

De outro lado, algumas dessas prestações representam, precisamente, o contrário da troca, inclusive para as prestações de coisas úteis: "Esses fatos respondem também a uma série de questões relativas às formas e às razões do que erroneamente é chamado de troca, 'o escambo', a 'permutatio’ das coisas úteis” (Idem, p. 302).

Mauss identifica nas prestações totais das sociedades antigas ou primitivas uma forma de relação que ele chama de "dádiva-troca" e que se diferencia da troca mercantil, na medida em que associa uma moral, um valor ético, à transação econômica. Ele usa, precisamente, a expressão de "moral da dádiva-troca":

O sistema que propomos chamar o sistema de prestações totais, de clã a clã - aquele no qual indivíduos e grupos trocam tudo entre si - constitui o mais antigo sistema de economia e de direito que podemos constatar e conceber. Ele forma o fundo sobre o qual se destacou a moral da dádiva-troca (Idem, p. 299).

Mauss diferencia essas dádivas de presentes, bens e símbolos da troca utilitarista. Para o autor, não são os indivíduos e sim as coletividades que mantêm obrigações de prestações recíprocas, mediante os grupos familiares, comunitários ou mediante seus chefes no caso do potlach: "Em primeiro lugar, não são indivíduos, são coletividades que se obrigam mutuamente, trocam e contratam [...]" (Idem, p. 190). Nessas prestações existem "misturas entre almas e coisas", entre riquezas materiais e espirituais, ao passo que nas sociedades modernas, direitos reais e direitos pessoais, material e espiritual, são muito bem separados. Assim ele descreve as oferendas mútuas:

Ademais, o que eles trocam não são exclusivamente bens, riquezas, bens moveis e imóveis, coisas úteis economicamente. São, antes de tudo, amabilidades, banquetes, ritos, serviços militares, mulheres, crianças, danças, festas [...].(Idem, ibidem).

Trata-se, no fundo, de misturas. Misturam-se as almas nas coisas, misturam-se as coisas nas almas (Idem, p. 212).

Com efeito, se material e espiritual se misturam, pode-se conceber que a coisa dada leva algo do ser do doador. Dessa forma Mauss faz uma distinção, em particular em sua análise do potlach e da dádiva agonística, entre a troca mercantil, motivada pelo interesse, e o sistema de dá- 
diva, no qual reina a nobreza e a honra e no qual o doador ganha prestígio. Para Temple e Chabal (1995, p. 19), se o autor interpreta a dádiva como um intercâmbio arcaico, não é no sentido utilitarista, em que o doador deveria recuperar seu bem, mas porque o donatário quer resguardar seu mana, seu prestígio, isto é, sua integridade espiritual:

Se coisas são dadas e retribuídas, é porque se dão e se retribuem "respeitos" - podemos dizer igualmente, "cortesias". Mas é também porque as pessoas se dão ao dar, e, se as pessoas se dão, é porque se "devem" - elas e seus bens - aos outros (Mauss, 2003, p. 263).

Vale lembrar que Mauss foi criticado por ter dado demasiada importância ao mana, Mas Temple e Chabal (1995) consideram, ao contrário, que Mauss percebera justamente que a matriz do laço entre as almas, do mana, se encontrava na obrigação de retribuir, na obrigação de reciprocidade. Contudo, de fato, a pesquisa de Mauss limitou-se apenas à reciprocidade das dádivas (isto é, a reciprocidade positiva, segundo a proposta de Temple e Chabal) e, por isso, não conduziu a uma teoria da reciprocidade. O mana expressaria o sentido dado ao homem ou criado pelo homem quando entra numa relação recíproca:

O mana é o valor da reciprocidade, um Terceiro entre os homens, que não está ainda aqui, mas para nascer, um fruto, um filho, o Verbo que circula (a Palavra), que dá a cada um seu nome de ser humano, e a sua razão ao universo (Idem, p. 15, tradução do autor).

Portanto, a análise de Mauss deve ser retomada e aprofundada numa direção diversa que aquela escolhida pelos teóricos da troca, a qual examinarei na segunda parte deste artigo.

Em síntese, pode-se concluir que as observações descritas no Ensaio... mostram que a dádiva equivale, para Mauss, a um crescimento da consciência de ser, a um incremento de autoridade e de fama para o doador. Dar não é mais oferecer algo de si, mas adquirir esse "si". O prestígio nasce da dádiva e relaciona-se àquele que toma a iniciativa: ao doador, para constituir seu próprio nome, sua fama, o valor de "renome" (Mauss, 2003, p. 258). Para Temple e Chabal, nesse sentido,
[...] a materialidade e a espiritualidade não estão mais ligadas a um estatuto comum de objeto, são opostas mediante dois estatutos, conjugados por uma relação de contradição: o espiritual aparece adquirido pelo doador, enquanto o material é adquirido pelo donatário. O uso da noção de troca não é mais necessário (1995, p. 26, tradução do autor).

De fato, para Mauss, nas dádivas, não existe nem troca, nem compra. A dádiva e a contradádiva, redescobertas por Mauss, pertencem a uma dialética social e econômica polarizada pelo prestígio e pela honra. Essa polaridade por si só proíbe reduzir o sistema dádiva/contradádiva a uma troca e reduzir o efeito de redobramento da dádiva ao interesse do primeiro doador.

\section{A questão da reciprocidade: o papel do terceiro}

O Ensaio sobre a dádiva é introduzido por um verdadeiro programa de pesquisa em torno de duas perguntas complementares: Por que as dádivas de presentes devem ser obrigatoriamente devolvidas? E por que existe essa universalidade da retribuição?

Nas palavras de Mauss: "Qual é a regra de direito e de interesse que, nas sociedades de tipo atrasado ou arcaico, faz que o presente recebido seja obrigatoriamente retribuído [...]. Que força existe na coisa dada que faz que o donatário a retribua?" (2003, p. 188). Segundo o autor, as dádivas voltam, são recíprocas e necessariamente devolvidas ou retribuídas. Mas a obrigação de retribuir parece desmentir a gratuidade das dádivas. Ela seria apenas aparente, ocultando uma troca interessada. Portanto, no início da explicação, ele mantém a tese da troca universal, situando a "dádiva-troca" como um ponto de passagem entre as prestações totais das sociedades arcaicas e os intercâmbios modernos. Assim, a história mostraria a evolução da troca a partir de prestações primitivas em que a comunicação entre os homens seria ao mesmo tempo material e simbólica - troca de bens e comunhão entre os seres - isto é, até a separação entre as comunicações espirituais, afetivas e materiais dos tempos modernos. Nas origens, 
segundo Mauss, interessa não somente as coisas, mas os seres, o ser:

Mas, por ora, é nítido que, em direito Maori, o vínculo de direito, vínculo pelas coisas, é um vínculo de almas, pois a própria coisa tem uma alma, é alma. Donde resulta que apresentar alguma coisa a alguém é apresentar algo de si (Idem, p. 200).

No entanto, essa coerência aparente da sua teoria deixa o próprio Mauss insatisfeito. Ele evoca várias vezes o vocabulário da troca e do interesse como palavras tipicamente européias que se aplicariam tão mal ao que pretendia dizer. Com efeito, lembram-nos Temple e Chabal (1995, p. 15), Mauss vai procurar uma palavra indígena para explicar que "os indígenas" fazem referência a um motor das prestações econômicas diferente do interesse. Motor ao qual Mauss dá um nome polinésio: o mana. O autor reconhece não poder reduzir o mana à noção de interesse econômico. Propõe, então, compará-lo a um capital imaginário, ao ser do doador. Mas, explicam Temple e Chabal, como a supremacia da sociedade ocidental sugere fortemente que a troca seja a forma mais evoluída das prestações humanas, a solução mais fácil para ligar troca e dádiva seria interpretar a reciprocidade das dádivas como uma troca arcaica. Precisaria, então, reduzir o mana, que segundo as referências indígenas comanda a reciprocidade, a um valor que pudesse ser trocado. Mauss atribui o mana ao doador, como uma propriedade espiritual; assim, dando algo, dá-se algo de si mesmo. A noção de dádiva de si leva à idéia de que a dádiva cria uma dependência para com o outro, porque o mana, o ser do doador, seria inalienável. Portanto, aquele que receberia esse símbolo seria obrigado a restituí-lo ou a ficar sob a sua dependência.

A interpretação que Mauss faz do hau Maori parece corroborar essa tese. O hau seria esse mana, a força de ser do doador que acompanha o bem dado e que, onde quer que esse vá, terá que voltar. Para Temple e Chabal, a questão do prestígio fica no coração de uma reflexão inacabada de Mauss. O hau maori e o mana polinésio seriam, segundo esses povos, a razão da circulação dos bens. Ora, Mauss observa que para dar conta dessa circulação os Maoris falam de um ciclo ternário: A dá a $\mathrm{B}$ que dá a C o qual devolve a B que dá de novo a A.
Mauss acredita que os Maori querem explicar a reciprocidade das dádivas dando uma expressão ao mana. Portanto, esse terceiro parceiro seria necessário para visualizar um valor moral. ${ }^{6} \mathrm{O}$ autor é levado assim a introduzir entre os parceiros um Terceiro de natureza ontológico, o mana ou o hau, isto é, o nome do doador. Porém a tese de Mauss, segundo Temple e Chabal, pode estar apenas incompleta, porque ele propõe também outra solução: o hau e o mana não constituem um valor já instituído como próprio do doador, mas, ao contrário, um valor produzido pela reciprocidade das dádivas, pelo movimento dos bens materiais ou simbólicos.

Nesse embate da reciprocidade, tal valor ético é compartilhado pelos protagonistas como um todo indiviso, invisível, um Terceiro incluído.? Para evidenciar esse "Terceiro" é possível recorrer a uma estrutura que não seja um artifício, como imagina Mauss, mas uma estrutura de reciprocidade bem concreta, ternária em vez de binária: precisamente a estrutura de reciprocidade simétrica.

Para Temple e Chabal essa interpretação tem o mérito de esclarecer como Ranaipiri - o sábio Maori - explica o funcionamento do hau para o etnólogo Rupert E. Best: "Esse texto [..] por momentos surpreendentemente claro oferece apenas uma obscuridade: a intervenção de uma terceira pessoa" (Mauss, 2003, p. 198).

Um fato importante no Ensaio sobre a dádiva é precisamente que para o essencial do que descobre e que não corresponde à lógica da troca moderna Mauss deixa falar os "indígenas". Quando introduz a expressão "manifestar respeitos recíprocos" (Idem, p 237) está traduzindo uma expressão dos índios Tlingit. Para qualificar o valor espiritual associado ao movimento das dádivas, ou para dar conta da necessidade do Terceiro, usa o mana ou a cara do mana. Para falar da figura desse Terceiro que assegura o laço espiritual, ele usa a expressão Kanak: "Nossas festas [a reciprocidade das dádivas] são o movimento da agulha que serve para ligar as partes do telhado de palha, para que haja um único teto, uma única palavra" (Idem, p. 213).

Mauss percebeu a preeminência da obrigação de retribuir (devolver), mas não tirou dessa observação o princípio de reciprocidade. Para Temple e Chabal (1995, p. 64), sua insistência em declarar essa obrigação irredutível aos dois ter- 
mos permite, no entanto, invocar uma estrutura mais fundamental que enlaça entre elas todo tipo de atividades (matrimônios, assassinatos, ${ }^{8}$ dádivas etc.), precisamente a estrutura de reciprocidade. Nas prestações totais, tudo é simbólico, diz Mauss, e tudo é recíproco.

\section{Síntese e ensinamentos}

Mauss chega a uma conclusão mestra: as dádivas vão e voltam sempre. "Pouco importa seu valor, pouco importa sua natureza; podem ser idênticas ou não; o importante é que recorram caminhos inversos ou simétricos, que elas se reproduzam como num espelho; e esta reflexão é o motor oculto dos seus movimentos, inclusive quando são aparentemente livres e gratuitas" (Temple e Chabal, 1995, p. 73, tradução do autor).

A devolução da dádiva é explicada pela força presente na coisa dada, pelo laço espiritual ao qual, na falta de um termo equivalente nos países ocidentais, Mauss dá o nome de mana ou que reconhece também no hau dos Maori. O prestígio não corresponde ao ego do doador, mas ao ser ao qual ele aspira, que não lhe preexiste e que deve ser produzido mediante a relação de reciprocidade (Temple e Chabal, 1995). Pois bem, a reciprocidade supõe uma preocupação pelo outro. Não se pode estar inquieto do outro sem se preocupar com suas condições de existência. Tal preocupação torna-se, portanto, hospitalidade, dádiva de alimentos e víveres, proteção, ou seja, motivos ou obrigações para produzir.

A partir das observações de Mauss sobre as dádivas, Temple (2003, Tomo 1, pp. 81-93) propõe uma regra de base da economia primitiva: se para ser é preciso dar, para dar, é necessário produzir. A produção de riquezas materiais é, assim, uma conseqüência da produção de energia espiritual, de mana. Mauss identificou a reciprocidade das dádivas, mas não o motor de uma economia de reciprocidade, porque no contexto em que vivia não existia outra possibilidade de evolução econômica, exceto a troca.

\section{Diferença entre troca e reciprocidade}

Como Lévi-Strauss (1997 [1950]) mostrou, a troca é, às vezes, chamada de recíproca porque, de fato, satisfaz o interesse de cada parceiro. Nesse caso, em que difere da reciprocidade? Precisamente porque a reciprocidade implica na preocupação pelo outro para estabelecer o mana, para produzir valores afetivos ou éticos como a paz, a confiança, a amizade e a compreensão mútua.

A troca utiliza esses primeiros valores humanos para se poupar da violência. Trata-se de uma relação de interesses, mas que supõe uma reciprocidade mínima. A razão aconselha estabelecer a competição de interesses forjada na confiança, na paz e na compreensão mútua produzidas pelas relações de reciprocidade. Dessa forma é possível entender que se possa muito facilmente confundir a troca com uma forma de reciprocidade simétrica. Mas, em realidade, ela inverte o movimento da reciprocidade, porque em vez de se preocupar com o outro, procura em primeiro lugar a satisfação do próprio interesse.

Segundo Temple e Chabal, Mauss reuniu as principais peças de uma teoria da reciprocidade: a dádiva, a obrigação de retribuir, o prestígio e a presença do terceiro, esse elemento que era "a única obscuridade da teoria indígena”. Mauss convence-se da idéia de que o ciclo das dádivas leva à obrigação de retribuir. No entanto, essa obrigação supõe uma estrutura fundamental de simetria entre as dádivas ou necessita que se recorra a um terceiro elemento, seja ele uma pessoa ou um símbolo. Pois o ele é um vinculo de almas, sendo a reciprocidade sua matriz, o princípio da sua gênese. No final de sua obra, Mauss percebe a origem natural da estrutura de reciprocidade nas condições do parentesco (exogamia e filiação):

[...] a separação por sexo, por gerações, por clãs, leva a fazer de um grupo A o associado de um grupo B, mas esses dois grupos, A e B, quer dizer as linhagens, são precisamente divididas por sexos e gerações: as oposições cruzam as coesões (Mauss, 1968-1969 [1931a], p. 141, tradução do autor).

Como escreve Laval (2006), para Mauss, a reciprocidade não se limita à dádiva entre pares, ela rege o princípio das relações entre grupos de idade e estatutos. Mauss diferencia assim a reciprocidade direta (prestações materiais ou simbólicas devolvidas entre dois indivíduos ou dois grupos) da reciprocidade indireta, quando os bens sim- 
bólicos recebidos não são devolvidos a quem os deu, mas a outro grupo que, por sua vez, terá que devolvê-los a um outro grupo. O modelo dessa reciprocidade indireta é precisamente aquele da circulação dos bens entre as gerações. "É aquilo que seu pai fez para você que você pode devolver ao seu filho" (Mauss, 1968-1969 [1931b]).

O que é recebido em termos de educação também deve ser devolvido (Laval, 2006). Essa estrutura de reciprocidade ternária, segundo Temple (1998), é aquela que reproduz também o sentimento e o valor ético de "responsabilidade" entre gerações. Aplicado aos recursos naturais, é essa mesma responsabilidade que levou as gerações passadas a preservar florestas, rios, lagos e mares. No fim da vida, Mauss pressentiu a universalidade desse princípio de reciprocidade quando discutiu a teoria educativa de Piaget:

[Ele] faz da noção de reciprocidade um privilégio do indivíduo saído da infância ou da sociedade já civilizada. Mas os fijianos, australianos [...] das grandes civilizações neolíticas já possuíam a noção de reciprocidade; no entanto a reciprocidade não quer dizer sempre igualdade. Da geração 1 à geração 2 , como da geração 2 à 3 , há reciprocidade, mas não igualdade; da mesma maneira entre homem e mulher (Mauss, 1968-1969 [1931a], p. 301, tradução do autor).

Como reconhece Laval, "podemos considerar que a transmissão cultural é estruturada segundo o princípio de reciprocidade indireta do qual Mauss foi o grande descobridor" (2006, p. 109). Mas, de fato, já na conclusão do Ensaio..., o autor explica essa moral da reciprocidade como matriz da humanidade:

Convém que o cidadão não seja nem demasiado bom e subjetivo demais, nem demasiado insensível e realista demais. É preciso que ele tenha um senso agudo de si mesmo, dos outros e da realidade social (e haverá, nesses fatos de moral uma outra realidade?). Ele deve agir levando em conta a si, os subgrupos e a sociedade. Essa moral é eterna; é comum às sociedades mais evoluídas, às do futuro próximo, e às sociedades menos educadas que possamos imaginar! Tocamos a pedra fundamental. Nem mesmo falamos mais em termos de direito, falamos de homens e de grupos de homens, porque são eles, é a sociedade, são os sentimentos de homens de carne, osso e espírito que agem o tempo todo e agiram em toda parte (Mauss, 2003, p. 299)

Isso quer dizer que o objetivo ético e político não é apenas assegurar as condições materiais de vida decentes para todos os seres humanos - para elas em si -, nem de garantir por si só a liberdade dos indivíduos psíquicos e coletivos, mas de assegurar a maximização da sua individualização no sentido de exprimir a sua singularidade, como garantia do seu pertencimento diferenciado a coletivos ou à totalidade humana.

\section{Considerações finais}

A intuição genial de Mauss foi a sua capacidade de vislumbrar a continuidade dessas categorias da dádiva do intercâmbio e da reciprocidade nas sociedades modernas:

Veremos a moral e a economia que regem essas transações. E, como constataremos que essa moral e essa economia funcionam ainda em nossas sociedades de forma constante e, por assim dizer, subjacente, como acreditamos ter aqui encontrado uma das rochas humanas sobre as quais são construídas as nossas sociedades, podemos deduzir disso algumas conclusões morais sobre alguns problemas colocados pela crise do nosso direito e da nossa economia [....] (Idem, p. 188).

Mauss via, também, na antiguidade e na universalidade de uma pluralidade de formas de mercados a estrutura da reciprocidade generalizada, antecipando as propostas mais recentes da economia solidária:

Nesses fenômenos sociais "totais" [...] exprimemse de uma só vez as mais diversas instituições: religiosas, jurídicas e morais, políticas e familiares [...] e econômicas - estas supondo formas específicas da produção e do consumo, ou melhor, do fornecimento e da distribuição [...] (Idem, p. 187).

O autor já reconhecia os valores e a dialética da dádiva, subjacente à estrutura econômica de redistribuição (ou de compartilhamento), das políticas de seguro social hoje tão ameaçadas:

Toda a nossa legislação de previdência social [...] 
inspira-se no seguinte princípio: o trabalhador deu sua vida e o seu trabalho à coletividade de um lado, a seus patrões, de outro e, se ele deve colaborar na obra de previdência, os que se beneficiaram de seus serviços não estão quites em relação a ele com o pagamento do salário. O próprio Estado, que representa a comunidade, devendolhe, com a contribuição dos patrões, uma certa seguridade em vida, contra o desemprego, a doença, a velhice e a morte (Idem, p. 296).

Temple e Chabal (1995) lembram na introdução do seu livro que uma objeção à tese de Mauss também poderia residir no fato de que, se as sociedades fundadas sobre a troca mercantil emergiram historicamente das sociedades organizadas pela reciprocidade, isto não significa necessariamente que a troca provenha da dádiva. Troca e dádiva podem ter coexistido e ter se afrontado desde as origens, e a troca triunfou, por exemplo, na sociedade ocidental. Precisamente, nas conclusões do Ensaio..., Mauss escreve a propósito da sociedade moderna:

Uma parte considerável de nossa moral e de nossa própria vida permanece estacionada nessa mesma atmosfera em que dádiva, obrigação e liberdade se misturam. Felizmente, nem tudo ainda é classificado exclusivamente em termos de compra e de venda. As coisas possuem ainda um valor sentimental além de seu valor venal, se é que há valores que sejam apenas desse gênero (Idem, p. 294).

Uma releitura do Ensaio sobre a dádiva, como do conjunto da obra de Mauss, ou por que não dizer de qualquer outro autor, deve, por suposto, ser situada no seu tempo. Assim, considero uma contribuição primordial de Mauss não apenas a qualificação da dádiva como forma de relação social e de transação econômica, mas, sobretudo, a universalidade da tríplice obrigação "dar, receber e retribuir" que permite hoje entender o princípio de reciprocidade como essa "rocha", matriz das relações e das civilizações humanas.

\section{Notas}

1 Refiro-me aos trabalhos recentes de Caillé (1998), Sigaud (1999), Lanna (2000), P. H. Martins (2001, 2002) e L. R. C. Oliveira (2004).
2 A troca, no sentido antropológico geral, é definida como "um termo aplicado a todo movimento de intenção recíproca entre duas partes" (Encyclopedia universalis, 1984, p. 897). Na economia, a troca corresponde a "diferentes modos de transferência de bens e de serviços realizados mediante contrapartida ou equivalência entre uns e outros" (Idem, p. 897).

3 Na antropologia, a reciprocidade foi muitas vezes limitada ao sistema "dádiva/contradádiva". Depois da contribuição de Mauss, ela foi associada ao conjunto de relações "dar, receber e retribuir", que corresponde à reciprocidade das dádivas (ou reciprocidade positiva). De fato, o princípio de reciprocidade é mais global e contempla também a reciprocidade negativa (a de vingança) e a reciprocidade simétrica. Neste sentido mais geral, tal conceito pode ser definido como uma relação mútua reversível entre dois sujeitos.

4 No conjunto dos textos do Ensaio sobre a dádiva, o termo reciprocidade aparece uma única vez, o adjetivo recíproco, quatro vezes, e a palavra troca (intercâmbio), mais de noventa vezes. De fato, Mauss designa por troca fatos bem diversos (desde a compensação material ate no sentido amplo de comunicação: o intercâmbio tece o laço social, está na base de todas as sociedades...), mas sem nunca definir esse conceito.

5 Os indígenas seriam os inventores da reciprocidade, como reconhece Lévi-Strauss na introdução à Sociologia e antropologia (2003).

6 Essa interpretação foi criticada por Lévi-Strauss (1997 [1950]). Segundo ele, os Maori, não sabendo reconhecer a troca como motor oculto da reciprocidade das dádivas, invocam um deus ex machina, o mana.

7 O Terceiro incluído seria "o que é, por si só, contraditório” da filosofia de Stéphane Lupasco (1987 [1951]).

8 A reciprocidade negativa, de acordo a Temple e Chabal (1995, pp. 81ss).

\section{BIBLIOGRAFIA}

CAILLÉ, Alain. (1998), "Nem holismo, nem individualismo metodológicos: Marcel Mauss e o paradigma da dádiva”. Revista Bra- 
sileira de Ciências sociais, 13 (38): 5-38, São Paulo.

ENCYCLOPÉDIA UNIVERSALIS. (1984), Encyclopédia universalis. Paris, Éditions Universalis, 20 vols.

GODBOUT, T. Jacques. (2000), "Le don, la dette et l'identité". Paris, La Découverte.

(2007), Ce qui circule entre nous: donner, recevoir, rendre. Paris, Le Seuil.

LANNA, Marcos. (2000), "Nota sobre Marcel Mauss e o Ensaio sobre a dádiva". Revista de Sociologia Política, 14: 173-194, Curitiba.

LAVAL, Christian. (2006), "Les deux crises de l'éducation". La Revue du MAUSS, 28: 96115.

LÉVI-STRAUSS, Claude. (1967 [1947]), Les structures élémentaires de la parenté. La Haye, Mouton.

. (1997 [1950]), "Introduction à l'œuvre de Marcel Mauss", in M. Mauss, Sociologie et anthropologie, 7 ed., Paris, PUF.

LUPASCO, Stéphane. ([1951] 1987), Le príncipe d'antagonisme et la logique de l'énergie, Paris, Edition Le Rocher.

MARTINS, Paulo Henrique. (2001), "A sociologia de Marcel Mauss e sua atualidade teórica: o paradigma da dádiva e as ciências sociais no Brasil". Trabalho apresentado no XXV Encontro Anual da Anpocs, Caxambu.

(org.). (2002), A dádiva entre os modernos. Petrópolis, Vozes.

MAUSS, Marcel. (1968-1969 [1931a]), Essais de sociologie. Paris, Éditions de Minuit (Tomos 1 e 2 de Oeuvres).

. (1968-1969 [1931b]). Euvres. Paris, Editions de Minuit, vol. 3.

(1997 [1950]), Essai sur le don: forme et raison de l'échange dans les sociétés archaïques, in Sociologie et anthropologie, Paris, PUF (ed. original: Année Sociologique, seconde série, tome 1, Paris, 1923-1924).

. (2003), Sociologia e antropologia. São

Paulo, Cosac e Naify.
OLIVEIRA, Luis Roberto Cardoso de. (2004), "Hon$\mathrm{ra}$, dignidade e reciprocidade", in $\mathrm{P}$. $\mathrm{H}$. Martins e B. Nunes (eds.), A nova ordem social: perspectivas da solidariedade contemporânea, São Paulo, Paralelo 15.

SIGAUD, Lygia. (1999), "As vicissitudes do Ensaio sobre o dom". Mana - Estudos de Antropologia Social, 5 (2): 89-124, Rio de Janeiro.

TEMPLE, Dominique. (1998), "Les structures élémentaires de la réciprocité". Revue du MAUSS, 12: 234-242, Paris.

(2003), Teoría de la reciprocidad. La Paz, Padep-GTZ [Tomo I: "La reciprocidad y el nacimiento de las valores humanos"; Tomo II: "La economía de reciprocidad"; Tomo III: "El frente de civilización"].

TEMPLE, Dominique \& CHABAL, Mireille. (1995), La réciprocité et la naissance des valeurs bumaines. Paris, L'Harmattan. 


\section{MARCEL MAUSS: DA DÁDIVA À QUESTÃO DA RECIPROCIDADE}

\section{Eric Sabourin}

Palavras chave: Dádiva; Troca; Reciprocidade; Marcel Mauss.

Por que da dádiva à reciprocidade? Porque, precisamente, ao longo do Ensaio sobre a dádiva, Marcel Mauss descreve relações e prestações de reciprocidade. Procurando explicar as origens humanas da troca, o autor descobre princípios fundamentais da organização e da lógica econômica e social das sociedades de reciprocidade. A dádiva e a contradádiva pertencem a uma dialética social e econômica polarizada pelo prestígio e pela honra. Essa polaridade, por si só, pró́be não só reduzir o sistema dádiva/contradádiva a uma troca (intercâmbio), mas também proíbe explicar o princípio de redobramento da dádiva pelo interesse do primeiro doador. O reconhecimento traduz-se em prestígio e em autoridade política. Mas, para poder dar, é preciso produzir: a produção está subordinada à doação, o que gera uma economia com princípios inversos àqueles da economia de troca ocidental.

MARCEL MAUSS: FROM THE GIFT TO THE ISSUE OF RECIPROCITY

\section{Eric Sabourin}

Keywords: Gift; Exchange; Reciprocity; Marcel Mauss.

Why from the gift to reciprocity? Because, precisely, along the Essay on the gift, Marcel Mauss describes relations and reciprocity provisions. In order to explain the human origins of exchanging, the author uncovers fundamental principles of the organization and economic and social logics in societies of reciprocity. Both the gift and the counter-gift belong to a social and economical dialectics polarized by prestige and honor. Such polarity, alone, not only forbids the simplification of the system gift/counter-gift to an exchange, but also the explanation of the principle of the gift redoubling on the interest of the first donor. Recognition renders prestige and political authority. However, in order to give, it is necessary to produce: such production is subordinated to the donation, which generates an economy with principles anatropous to those of the exchange-based occidental economy.
MARCEL MAUSS : DU DON À LA QUESTION DE LA RÉCIPROCITÉ

\section{Eric Sabourin}

Mots-clés: Don; Échange; Réciprocité; Marcel Mauss.

Pourquoi le don de la réciprocité? Car, spécifiquement, au long de l'Essai sur le don, Marcel Mauss décrit les liens et les prestations de réciprocité. Cherchant à expliquer les origines humaines de l'échange, l'auteur découvre des principes fondamentaux de l'organisation et de la logique économique et sociale des sociétés de réciprocité. Le don et le contre-don appartiennent à une dialectique sociale et économique polarisée par le prestige et par l'honneur. Cette polarité interdit, à elle seule, non seulement de réduire le système don/contre-don à un échange, mais interdit aussi d'expliquer le principe de redoublement du don à cause de l'intérêt du premier donneur. La reconnaissance se traduit en prestige et en autorité politique. Mais, pour pouvoir donner, il faut produire: la production est subordonnée à la donation, ce qui gère une économie de principes inverses à ceux de l'économie d'échange occidentale. 